\title{
ARTICLE
}

Received 27 Feb 2014 | Accepted 19 Jun 2014 | Published 21 Jul $2014 \quad$ DOl: 10.1038/ncomms5460

\section{Ultra-sensitive optical oxygen sensors for characterization of nearly anoxic systems}

Philipp Lehner ${ }^{1}$, Christoph Staudinger ${ }^{1}$, Sergey M. Borisov ${ }^{1} \&$ Ingo Klimant ${ }^{1}$

Oxygen quantification in trace amounts is essential in many fields of science and technology. Optical oxygen sensors proved invaluable tools for oxygen measurements in a broad concentration range, but until now neither optical nor electrochemical oxygen sensors were able to quantify oxygen in the sub-nanomolar concentration range. Herein we present new optical oxygen-sensing materials with unmatched sensitivity. They rely on the combination of ultra-long decaying (several $100 \mathrm{~ms}$ lifetime) phosphorescent boron- and aluminiumchelates, and highly oxygen-permeable and chemically stable perfluorinated polymers. The sensitivity of the new sensors is improved up to 20-fold compared with state-of-the-art analogues. The limits of detection are as low as 5 p.p.b., volume in gas phase under atmospheric pressure or $7 \mathrm{pM}$ in solution. The sensors enable completely new applications for monitoring of oxygen in previously inaccessible concentration ranges.

\footnotetext{
${ }^{1}$ Institute of Analytical Chemistry and Food Chemistry, Graz University of Technology, NAWI Graz, Stremayrgasse 9, 8010 Graz, Austria. Correspondence and requests for materials should be addressed to S.M.B. (email: sergey.borisov@tugraz.at).
} 
xygen undoubtedly belongs to the most important analytes on earth. Traditionally, most oxygen sensors were designed for the physiological range. However, numerous applications require monitoring of oxygen at significantly lower concentrations, for example, corrosion protection $^{1}$, surface treatment ${ }^{2}$, the semiconductor industry ${ }^{3}$ and biological research. For instance, it was demonstrated that bacteria can show respiration and potentially aerobic growth far below the Pasteur point $(\sim 10 \mu \mathrm{M} \text { dissolved oxygen (DO) })^{4-6}$. Recently, sensors that quantify DO in concentration ranges of $100 \mathrm{nM}$ and below have gained special interest as biologists explore aerobic life in areas very close to anoxic conditions ${ }^{7}$. Unfortunately, few sensors are capable to resolve at such low concentration $^{8,9}$, and measurements below $0.5 \mathrm{nM}$ are currently impossible.

Optical sensors proved to be indispensable tools for oxygen quantification that have mostly replaced the more conventional Clark electrode. Their advantages include minimal invasiveness, simplicity, suitability for miniaturization, versatility of formats (planar optodes, fibre-optic sensors, micro- and nanoparticles, paints and so on) and suitability for imaging of oxygen distribution on surfaces or in volume. Moreover, optical oxygen sensors are tuneable over a wide range of concentrations. Optical oxygen sensors rely on quenching of a phosphorescent indicator by the analyte. Both the nature of the indicator and the matrix (which acts as a solvent and support for the dye and as a permeation-selective barrier) are of great importance since the sensitivity of an oxygen sensor is roughly proportional to the luminescence decay time of the indicator and to the oxygen permeability of the matrix ${ }^{10}$. State-of-the-art indicators are dominated by phosphorescent complexes with platinum group metals that possess decay times varying from microseconds to a few milliseconds ${ }^{11-14}$. Dyes with significantly longer decay times are extremely rare and are so far limited to fullerenes ${ }^{9,15}$ (which have rather low luminescence brightness at ambient temperatures) and some phosphorescent $\mathrm{BF}_{2}$-chelates ${ }^{16-19}$. Both classes are not inherently compatible with highly oxygenpermeable matrices (for example, silicone and Teflon AF). Hence, the sensors based on these indicators and other matrices (for example, ethylcellulose and polystyrene (PS) $)^{9}$ are not drastically more sensitive than sensors relying on more conventional dyes (for example, Pd(II) porphyrins) immobilized in highly oxygen-permeable polymers ${ }^{20}$.

Herein, we present a new type of oxygen-sensing materials that show sensitivities well beyond state-of-the-art trace oxygen sensors. They rely on new blue light-excitable $\mathrm{BF}_{2}$ and $\mathrm{Al}(\mathrm{III})$ chelates featuring ultra-long room temperature phosphorescence. The chelates are modified with perfluoroalkyl chains to ensure compatibility with highly oxygen-permeable and chemically inert perfluorinated polymers. The resulted ultra-sensitive sensors are ideally suitable for characterization of nearly anoxic systems.

\section{Results}

Photophysical properties. The new-sensing materials rely on novel difluoroboron- and aluminium chelates of 9-hydroxyphenalenone (HPhN; Fig. 1$)^{21}$ and its benzannelated derivative 6-hydroxybenz[de]anthracene-7-on (HBAN; scheme 1; ref. 22). In contrast to the common fluorescent difluoroboron chelates of dipyrromethenes and tetraarylazadipyrromethenes ${ }^{23,24}$, the new difluoroboron-based dyes simultaneously show prompt fluorescence, delayed fluorescence and phosphorescence when embedded in polymers (Fig. 2a,b). Room temperature phosphorescence is an extremely rare phenomenon for compounds with no heavy atoms. It was previously observed for $\mathrm{BF}_{2}$-chelates of aliphatic $\beta$-diketones coupled to polylactic $\operatorname{acid}^{16,17}$ or physically entrapped in the same polymer ${ }^{19}$. This work and our results indicate that phosphorescence of aliphatic and aromatic $\mathrm{BF}_{2}$-chelates of $\beta$-diketones appears to be a general phenomenon. As can be seen, the extension of $\pi$-conjugation in $\mathrm{HPhN}$ derivatives results in bathochromic shifts of absorption, fluorescence and phosphorescence compared with the reported aliphatic diketonate chelates. In fact, the absorption of the HPhN and HBAN difluoroboron chelates peaks at 450 and $459 \mathrm{~nm}$, respectively, $\left(\varepsilon_{450}=10.2 \times 10^{3} \mathrm{M}^{-1} \mathrm{~cm}^{-1}\right.$ and $\varepsilon_{459}=12.9$ $\left.\times 10^{3} \mathrm{M}^{-1} \mathrm{~cm}^{-1}\right)$. This enables excitation with bright blue 450 and $470 \mathrm{~nm}$ LEDs and with conventional white light sources. Temperature affects the quantum yields of all three emissions.

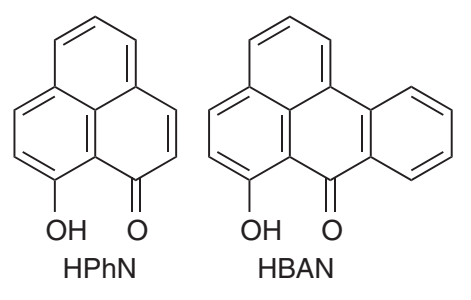<smiles>O=C1c2ccccc2-c2c(C(F)(F)F)ccc3c(C(F)(F)F)cc(O)c1c23</smiles>

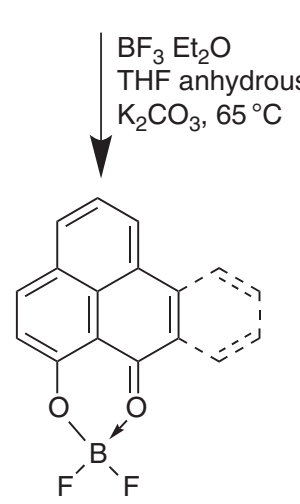<smiles>C1CCCCC1</smiles>

$\mathrm{BF}_{3} \mathrm{Et}_{2} \mathrm{O}$ THF anhydrous $\mathrm{K}_{2} \mathrm{CO}_{3}, 65^{\circ} \mathrm{C}$

HPhNPF/HBANPF<smiles>CCCCCCCC(C)C(F)(F)F</smiles>

$\mathrm{AlCl}_{3}$ THF, EtOH (50/50) $\mathrm{NaOH}, 40^{\circ} \mathrm{C}$ $\checkmark$<smiles>O=C1C2=C(COC=C2)c2c(C(F)(F)F)ccc3c(O[AlH2])cc(C(F)(F)F)c1c23</smiles>

$\mathrm{BF}_{2}(\mathrm{HPhN}) / \mathrm{BF}_{2}(\mathrm{HBAN})$

$\mathrm{BF}_{2}(\mathrm{HPhNPF}) / \mathrm{BF}_{2}(\mathrm{HBANPF})$

$\mathrm{Al}(\mathrm{HPhNPF})_{3} / \mathrm{Al}(\mathrm{HBANPF})_{3}$

Figure 1 | Synthesis of the borondifluoride chelates and aluminium complexes. 

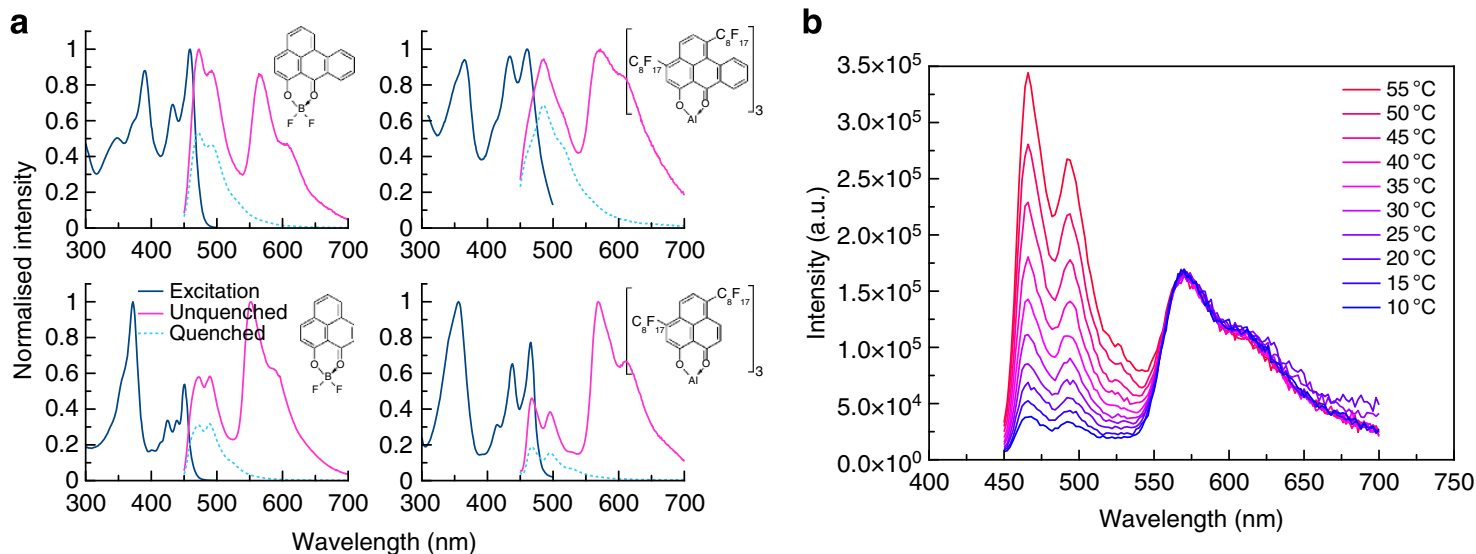

Figure 2 | Spectral properties of the oxygen indicators. (a) Excitation and emission spectra of HBAN and HPhN difluoroboron chelates in PS and aluminium complexes in Teflon AF 1600. (b) Temperature-dependent emission spectra of AI(HPhNPF) 3 in Hyflon AD 60 under deoxygenated conditions acquired with a delay of $0.5 \mathrm{~ms}$ after excitation.

Table 1 | Photophysical and sensing properties of trace oxygen sensors at $20^{\circ} \mathrm{C}$.

\begin{tabular}{|c|c|c|c|c|c|c|}
\hline Sensor material & Absorption max. (nm) ${ }^{\star}$ & Emission max. (nm) & $\Phi(\%)^{\dagger}$ & $\tau_{0}$ (ms) & $K_{\mathrm{sv}}\left(10^{-3}\right)$ p.p.m. v. ${ }^{-1}$ & References \\
\hline Pd-TPFPP in silica gel & 410 & 670 & ND & 0.978 & 7 & 31 \\
\hline$C_{70}$ in ethylcellulose & 470 & 710 & $1^{\ddagger}$ & $20-25$ & 75 & 15 \\
\hline${ }^{13} C_{70}$ in ethylcellulose ${ }^{\S}$ & 470 & 710 & ND & 28 & 48 & 9 \\
\hline $\mathrm{BF}_{2}(\mathrm{HPhN})$ in polystyrene & 450 & 552 & 4.6 & 360 & 60 & This work \\
\hline $\mathrm{BF}_{2}(\mathrm{HBAN})$ in polystyrene & 459 & 565 & 9.1 & 730 & 120 & This work \\
\hline $\mathrm{Al}(\mathrm{HPhNPF})_{3}$ in Hyflon AD 60 & 465 & 570 & ND & 270 & 420 & This work \\
\hline $\mathrm{Al}(\mathrm{HBANPF})_{3}$ in Hyflon AD 60 & 459 & 565 & ND & 400 & 590 & This work \\
\hline $\mathrm{Al}(\mathrm{HPhNPF})_{3}$ in Teflon AF 1600 & 465 & 570 & 5.4 & 250 & 920 & This work \\
\hline $\mathrm{Al}(\mathrm{HBANPF})_{3}$ in Teflon AF 1600 & 459 & 575 & 3.2 & 350 & 960 & This work \\
\hline
\end{tabular}

As expected, the phosphorescence QYs decrease at higher temperature and the delayed fluorescence becomes stronger (Fig. 2b). Since both phosphorescence and delayed fluorescence possess virtually identical decay times (Supplementary Fig. 1) and are quenched by oxygen to the same extent, their ratio can be used to eliminate temperature crosstalk. Importantly, prompt fluorescence is suitable for referencing purposes, as it is not affected by oxygen. However, the most outstanding property of these dyes is their extraordinary long phosphorescence decay time of 360 and $730 \mathrm{~ms}$ for $\mathrm{BF}_{2}(\mathrm{HPhN})$ and $\mathrm{BF}_{2}(\mathrm{HBAN})$, respectively (in PS at $20^{\circ} \mathrm{C}$ ), which, to the best of our knowledge, are the longest decay times recorded for visible light-excitable dyes. This is likely due to the rigid aromatic backbone structure of the dyes. Despite those long decay times, the phosphorescence quantum yields are fairly high (Table 1 and Supplementary Table 1).

Ultra-sensitive oxygen-sensing materials. Owing to the exceptionally long lifetimes of these chelates, resulting sensing materials are expected to have sensitivities orders of magnitude above those based on conventional sensing chemistries. Indeed, sensors composed of difluoroboron chelates in PS show very high sensitivities, even though PS has only moderate oxygen permeability $\left(P \approx 8.8 \times 10^{-16} \mathrm{~mol} \mathrm{~m}^{-1} \mathrm{~s}^{-1} \mathrm{~Pa}^{-1}\right.$; ref. 25) $K_{\mathrm{SV}}$ for $\mathrm{BF}_{2}(\mathrm{HPhN})$ - and $\mathrm{BF}_{2}(\mathrm{HBAN})$-based sensors was $60 \times 10^{-3}$ and $120 \times 10^{-3}$ p.p.m.v. ${ }^{-1}$, respectively, (Fig. 3a), which makes them suitable for monitoring sub-nanomolar DO concentrations. The limit of detection for the $\mathrm{BF}_{2}(\mathrm{HBAN})$-based material, assuming a resolution of $0.5 \% I_{0}$, is in fact 45 p.p.b.v. (gas phase) or $60 \mathrm{pM}$ (DO). Both sensing materials surpass the sensitivity of nearly all previously published sensors. Still, highly permeable matrices such as Hyflon, Teflon AF and poly(trimethylsilylpropyne) can potentially be used to create even more sensitive materials. Poly(trimethylsilylpropyne) has the highest known oxygen permeability $\left(P \approx 23,000 \times 10^{-16} \mathrm{~mol}\right.$ $\mathrm{m}^{-1} \mathrm{~s}^{-1} \mathrm{~Pa}^{-1}$; ref. 26) but was not considered because of poor chemical stability and possession of double bonds that are prone to oxidation and thus analyte consumption ${ }^{27,28}$. Hyflon and Teflon AF are amorphous, glassy, perfluorinated copolymers that combine high free volume and unmatched chemical stability. In this work we used Hyflon AD $60\left(P \approx 170 \times 10^{-16} \mathrm{~mol} \mathrm{~m}^{-1} \mathrm{~s}^{-1}\right.$ $\mathrm{Pa}^{-1}$; ref. 29$)$ and Teflon AF $1600\left(P \approx 1,200 \times 10^{-16} \mathrm{~mol} \mathrm{~m}^{-1}\right.$ $\mathrm{s}^{-1} \mathrm{~Pa}^{-1}$; ref. 30$)$. Unfortunately, most conventional dyes, as well as $\mathrm{BF}_{2}(\mathrm{HPhN})$ and $\mathrm{BF}_{2}(\mathrm{HBAN})$, show extremely poor solubility in these matrices and aggregate readily. We failed to obtain usable sensors based on the $\mathrm{BF}_{2}$-chelates due to poor luminescence in perfluorinated polymers at any relevant concentration $(0.01-1 \%$ wt. of the dyes in respect to the polymer). Therefore, in order to render the indicators soluble in Hyflon and Teflon $\mathrm{AF}, \mathrm{HPhN}$ and HBAN were perfluoroalkylated with perfluorooctyl iodide (scheme 1). The resulting ligands 9-hydroxy-4,7-diperfluorooctyl1H-phenalenone (HPhNPF) and 6-hydroxy-1,4-diperfluorooctyl7H-benzo[de]anthracen-7-one (HBANPF) bear two $\mathrm{C}_{8} \mathrm{~F}_{17}$ chains each, although in the case of HBANPF there is some impurity of tri-substituted ligand (Supplementary Figs 2 and 3). As indicated by nuclear Overhauser effect spectroscopy (NOESY) and heteronuclear multiple-bond correlation spectroscopy (HMBC) spectra 
a
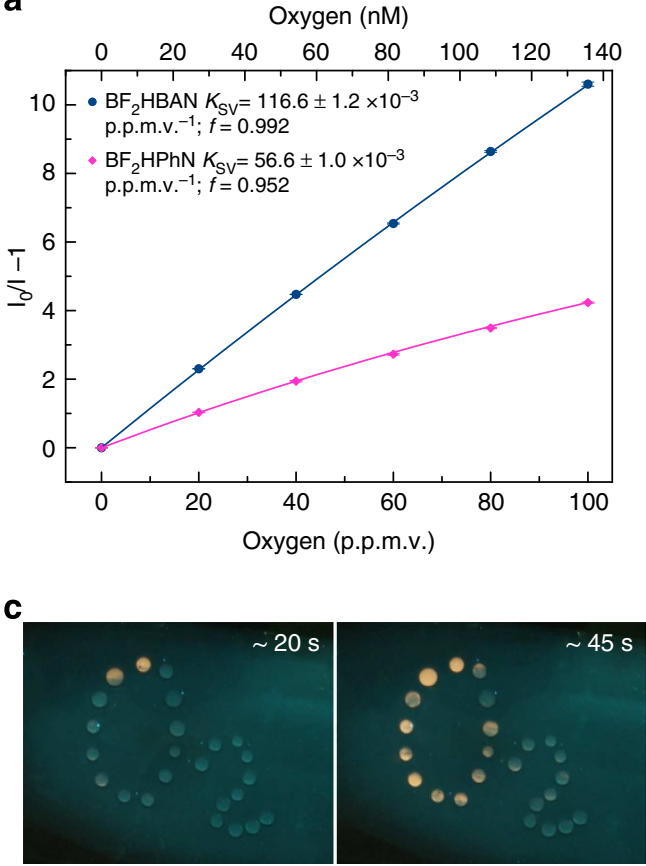

b

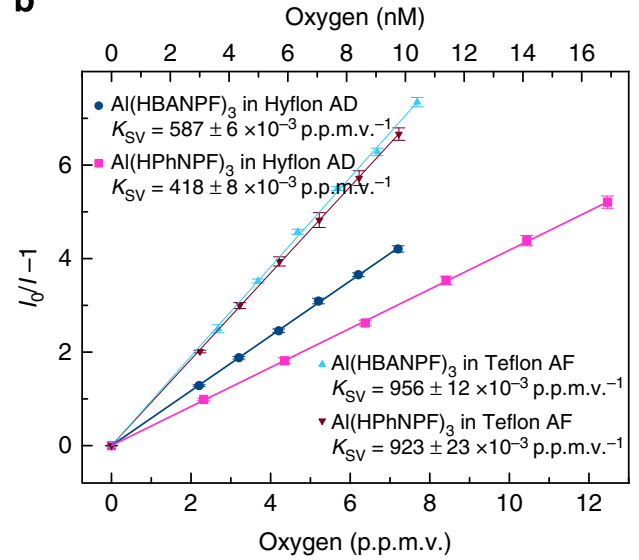

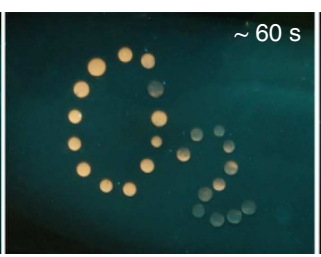

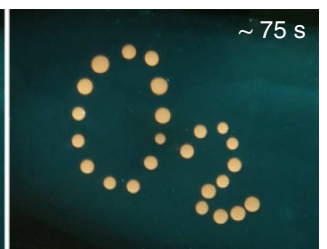

Figure 3 | Oxygen sensitivity of the trace sensors at $20^{\circ} \mathbf{C}$. (a) Stern-Volmer plots for $\mathrm{BF}_{2} \mathrm{HBAN}$ and $\mathrm{BF}_{2} \mathrm{HPhN}$ in PS. (b) Stern-Volmer plots for the aluminium complexes. (c) Photographic images of the AI(HPhNPF) $)_{3} /$ Hyflon AD 60 sensor under illumination with a 366-nm line of a ultraviolet lamp. Bluish prompt fluorescence remains constant, and the intense yellow phosphorescence slowly appears for the areas covered with anaerobic sodium sulphite solution ( $5 \% \mathrm{wt}$, containing traces of $\mathrm{Co}^{2+}$ as a catalyst).

(Supplementary Figs 4 and 5), a single isomer appears to be the predominant product for HPhNPF (Supplementary Fig. 6). The ${ }^{1} \mathrm{H}$ nuclear magnetic resonance (NMR) and correlation spectroscopy (COSY) spectra for HBANPF (Supplementary Figs 7 and 8) showed no significant substitution in the benzannelated ring. Complete separation of the tri-substituted derivate is very challenging owing to the very high similarity; however, both triand disubstituted derivates are expected to have very similar photophysical properties und solubility. It was found that perfluoroalkylated derivates of the difluoroboron chelates have low chemical stability and dissociate in solution in presence of traces of water (Supplementary Fig. 9). Hence, aluminium complexes $\left(\mathrm{Al}(\mathrm{HPhNPF})_{3}\right.$ and $\mathrm{Al}(\mathrm{HBANPF})_{3}$; scheme 1$)$ were prepared in an attempt to obtain more stable indicators. Indeed, dissociation was not observed for the aluminium chelates and they dissolve readily in fluorinated solvents (octafluorotoluene and perfluorodecalin) and also in Hyflon and Teflon AF. Owing to the octahedral structure of the $\mathrm{Al}(\mathrm{III})$ complexes and unsymmetric substitution pattern of the ligands four sterioisomers are possible, which are inseparable because of their extreme similarity. The photophysical properties of the isomers are expected to be virtually identical. Similar to the $\mathrm{BF}_{2}$-chelates, the $\mathrm{Al}(\mathrm{III})$ complexes possess prompt fluorescence, delayed fluorescence and phosphorescence (Fig. 1). The phosphorescence decay times $(250 \mathrm{~ms}$ for $\mathrm{Al}(\mathrm{HPhNPF})_{3}$ and $350 \mathrm{~ms}$ for $\mathrm{Al}(\mathrm{HBANPF})_{3}$ at $20^{\circ} \mathrm{C}$ in Teflon $\mathrm{AF}$ 1600) are slightly shorter than those of the $\mathrm{BF}_{2}$-chelates, and the $\mathrm{Al}(\mathrm{III})$ complexes possess higher molar absorption coefficients $\left(\varepsilon_{465}=23.2 \times 10^{3} \mathrm{M}^{-1} \mathrm{~cm}^{-1}\right.$ and $\varepsilon_{459}=27.1 \times 10^{3} \mathrm{M}^{-1} \mathrm{~cm}^{-1}$ for $\mathrm{Al}(\mathrm{HPhNPF})_{3}$ and $\mathrm{Al}(\mathrm{HBANPF})_{3}$, respectively). The oxygensensing materials based on these Al(III) complexes embedded in Hyflon show extremely high sensitivities (Fig. 3b). In fact, the $K_{\mathrm{SV}}$ values are as high as $590 \times 10^{-3}$ p.p.m. v. ${ }^{-1}$ (for $\mathrm{Al}(\mathrm{HBANPF})_{3}$, Table 1) and the sensors resolve up to 10 p.p.b.v. or $12 \mathrm{pM} \mathrm{DO}$. They are about one order of magnitude more sensitive than the state-of-the-art sensors based on fullerenes (Table 1$)^{14}$. The sensors based on Teflon AF 1600 show a twofold increase in sensitivity compared with the Hyflon-based ones. $\mathrm{Al}(\mathrm{HBANPF})_{3}$ in Teflon AF 1600 is the most sensitive sensor material presented, with a $K_{\mathrm{SV}}$ of $960 \times 10^{-3}$ p.p.m.v. ${ }^{-1}$ and a detection limit of 5 p.p.b.v. or $7 \mathrm{pM}$. Potentially, even more sensitive sensor materials based on Teflon AF $2400\left(P \approx 3000 \times 10^{-16} \mathrm{~mol} \mathrm{~m}^{-1} \mathrm{~s}^{-1} \mathrm{~Pa}^{-1}\right.$; ref. 30$)$ showed signs of aggregation and were therefore not further investigated. Importantly, the Stern-Volmer plots for the phosphorescence decay time are similar to those obtained for the intensity measurements (Fig. 3 b and Supplementary Fig. 10) so both read-out schemes (ratiometric intensity or decay time) can be used. It should be mentioned that sensitivities are so high that obtaining reliable calibrations becomes rather challenging. Even high-purity nitrogen contains oxygen impurities in the low p.p.m. range, hence all aluminium complex-based sensor materials were calibrated using a standard addition method described in the experimental section.

Temperature is known to affect the response of all optical sensors; thus the temperature dependence of the new sensors was investigated (Supplementary Fig. 11). In contrast to most oxygen sensors, the Stern-Volmer constants $K_{\mathrm{SV}}$ decrease at higher temperature. This can be explained by a relatively strong effect of temperature on the phosphorescence decay time $\tau_{0}(280,250$ and $220 \mathrm{~ms}$ at 5,20 and $35^{\circ} \mathrm{C}$, respectively, for $\mathrm{Al}(\mathrm{HPhNPF})_{3}$ in Hyflon $\mathrm{AD}$ 60) and a negligible influence on the bimolecular quenching constant $k_{\mathrm{q}}\left(1.65,1.65\right.$ and 1.69 p.p.m. v. ${ }^{-1} \mathrm{~ms}^{-1}$ at 5 , 20 and $35^{\circ} \mathrm{C}$, respectively). This indicates that in contrast to most polymers, the oxygen permeability of Hyflon $\mathrm{AD} 60$ appears to be barely affected by temperature.

Application example. To illustrate potential applications of these trace oxygen sensors, the kinetics of oxygen consumption during enzymatic oxidation of glucose was monitored as it approached anoxic conditions (Fig. 4). Aqueous solutions of glucose oxidase, catalase and glucose were combined in a closed stirred vessel, and the oxygen concentration was monitored with a set of sensors with overlapping ranges. In addition to the $\mathrm{Al}(\mathrm{HPhNPF})_{3} / \mathrm{Hyflon}$ 


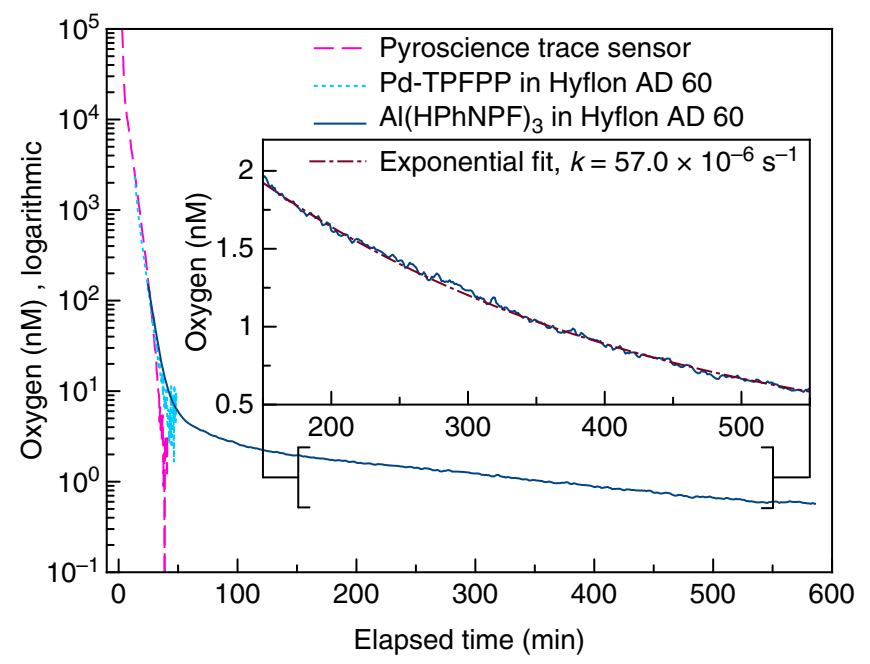

Figure 4 | Real-time monitoring of oxygen levels during enzymatic oxygen consumption. Three trace sensors with overlapping ranges are used to monitor oxidation of glucose catalysed by glucose oxidase. A running average of 3 data points was used for all sensors. Whereas, the reference sensors fail to resolve below 2-10 nM; the new ultra-trace sensor can reliably monitor oxygen even at much lower concentrations (insert).

sensor, two other oxygen sensors were used: a commercially available trace sensor from Pyroscience $\mathrm{GmbH}$ and a sensor based on $\operatorname{Pd}(\mathrm{II})-5,10,15,20$-meso-tetrakis-(2,3,4,5,6-pentafluorphenyl)porphyrin in Hyflon, which is comparable in sensitivity to previously published sensors ${ }^{31}$. Figure 4 shows the high resolution of the new sensors in the ultra-trace region, whereas the other sensors fail to resolve oxygen concentrations below $1 \mathrm{nM}$. The insert shows a mono-exponential fit of the ultra-trace region corresponding to purely diffusion-controlled depletion of oxygen.

Precise quantification of oxygen impurity in inert gases represents another potential application of the new sensors. The $\mathrm{Al}(\mathrm{HPhNPF})_{3} /$ Hyflon sensor was used to quantify oxygen content in high-purity gases obtained from Linde (Austria). For example, two samples of compressed nitrogen 5.0 (99.999\%, <10 p.p.m.v. $\mathrm{O}_{2}$ ) contained 3.7 and 2.5 p.p.m.v. $\mathrm{O}_{2}$, whereas compressed nitrogen $6.0\left(99.9999 \%\right.$, < 1 p.p.m.v. $\left.\mathrm{O}_{2}\right)$ contained 0.52 p.p.m.v. $\mathrm{O}_{2}$, which is within the specifications of the gas manufacturer.

\section{Discussion}

We prepared new optical oxygen-sensing materials with unmatched sensitivity. The most sensitive shows an $\sim 20$-fold increase in sensitivity compared with state-of-the-art materials. Such extraordinary high-sensitivity results from the combination of extremely long phosphorescence decay times of the indicators and very high oxygen permeability of the matrix. Novel heavy metal-free chelates of rigid aromatic analogues of $\beta$-diketones represent unique indicators for oxygen sensors that feature absorption in the blue part of the electromagnetic spectrum, very long-decaying room temperature phosphorescence, good molar absorption coefficients and adequate quantum yields. The unique dual emission of the chelates (delayed fluorescence and phosphorescence) can be used for intrinsic temperature compensation. These sensors enable completely new applications for monitoring of oxygen in previously inaccessible concentration regions, and are likely to become invaluable tools in various fields of science and technology.

\section{Methods}

Materials. Nitrogen $\left(99.9999 \%\right.$ purity) and test gases (1,000 p.p.m.v. $\mathrm{O}_{2}$, rest $\mathrm{N}_{2}$; and 20 p.p.m.v. $\mathrm{O}_{2}$, rest $\mathrm{N}_{2}$ ) were obtained from Linde Gas (Austria; www.linde.at), PS (molecular weight (MW) 250,000) and hydrogen peroxide (60\%) were obtained from Fisher Scientific. Perfluorooctyl iodide and aquaphobe CF were bought from ABCR (Germany; www.abcr.de). Teflon AF 1600 was acquired from DuPont (USA www.dupont.com). Hyflon AD 60 was obtained from Solvay (USA; www.solvayplastics.com). Sodium sulphite was obtained from Carl Roth (www. carlroth.com). Boron trifluoride diethyl etherate, aluminium oxide (activated, neutral Brockmann I), aluminium(III) chloride, 1,1,2-trichloro-1,2,2trifluoroethane (Freon 113), glucose oxidase from Aspergillus niger, catalase from bovine liver, anhydrous tetrahydrofuran (THF) and anhydrous dimethylsulphoxide were obtained from Aldrich, iron(II) sulphate heptahydrate from Merck, sodium hydroxide from Lactan (Austria; www.lactan.at) and silicon E4 from Wacker (Germany; www.wacker.de). Acetone and ethanol were acquired from Brenntag (Germany; www.brenntag.de), and other solvents including the deuterated solvents were from VWR (Austria; www.at.vwr.com). HPhN was obtained from Ramidus (Sweden; www.ramidus.se) and HBAN was synthesized according to the literature procedure ${ }^{22}$.

Synthesis of the $\mathbf{B F}_{\mathbf{2}}$ chelate of $\mathbf{H P h N}$. An amount of $294 \mathrm{mg}(1.5 \mathrm{mmol})$ of $\mathrm{HPhN}$ were dissolved in $50 \mathrm{ml}$ of anhydrous THF and $1.92 \mathrm{~g}(13.5 \mathrm{mmol})$ of boron trifluoride diethyl etherate were added. The solution was stirred for $1 \mathrm{~h}$ at $65^{\circ} \mathrm{C}$, the solvent was removed under vacuum and the product was purified on an aluminium oxide column using dichloromethane as an eluent. Yield: $300 \mathrm{mg}(67 \%)$ of orange crystals. ${ }^{1} \mathrm{H}$ NMR $\left(300 \mathrm{MHz}, \mathrm{DMSO}-\mathrm{d}_{6}, \delta\right): 8.94(\mathrm{~d}, J=9.1 \mathrm{~Hz}, 2 \mathrm{H}), 8.70(\mathrm{~d}$, $J=7.7 \mathrm{~Hz}, 2 \mathrm{H}), 8.03(\mathrm{t}, J=7.7 \mathrm{~Hz}, 1 \mathrm{H}), 7.62(d, J=9.1 \mathrm{~Hz}, 2 \mathrm{H})$. Electron impactdirect injection-time of flight (EI-DI-TOF) $(\mathrm{m} / \mathrm{z})$ : found 244.0499, calculated 244.0510 .

Synthesis of the $\mathbf{B F}_{\mathbf{2}}$ chelate of HBAN. A quantity of $369 \mathrm{mg}(1.5 \mathrm{mmol})$ of HBAN were dissolved in $60 \mathrm{ml}$ of anhydrous THF, and $1.7 \mathrm{~g}(12 \mathrm{mmol})$ of boron trifluoride diethyl etherate were added. The solution was stirred at $65^{\circ} \mathrm{C}$ for $2 \mathrm{~h}$, and $69 \mathrm{mg}(0.5 \mathrm{mmol})$ of potassium carbonate were added and the stirring was continued for $2 \mathrm{~h}$. The solvent was removed under vacuum and the product was purified on an aluminium oxide column using dichloromethane as an eluent. Yield: $340 \mathrm{mg}(77 \%)$ of orange crystals. ${ }^{1} \mathrm{H}$ NMR $\left(300 \mathrm{MHz}, \mathrm{DMSO}-\mathrm{d}_{6}, \delta\right): 9.26(\mathrm{~d}$, $J=7.7 \mathrm{~Hz}, 1 \mathrm{H}), 9.04(\mathrm{~d}, J=8.3 \mathrm{~Hz}, 1 \mathrm{H}), 8.91(\mathrm{~d}, J=9.2 \mathrm{~Hz}, 1 \mathrm{H}), 8.69(\mathrm{~d}, J=8.2 \mathrm{~Hz}$, $1 \mathrm{H}), 8.50(\mathrm{~d}, J=7.6 \mathrm{~Hz}, 1 \mathrm{H}), 8.21(\mathrm{t}, J=8.3 \mathrm{~Hz}, 1 \mathrm{H}), 7.97(\mathrm{dt}, J=21.2,7.6 \mathrm{~Hz}, 2 \mathrm{H})$, $7.61(\mathrm{~d}, J=9.1 \mathrm{~Hz}, 1 \mathrm{H})$. EI-DI-TOF $(\mathrm{m} / \mathrm{z})$ : found 294.0671 , calculated 294.0667 .

Synthesis of HPhNPF. HPhN (1 g, $5.1 \mathrm{mmol})$ and $\mathrm{FeSO}_{4} 7 \mathrm{H}_{2} \mathrm{O}(2.5 \mathrm{~g}, 9.0 \mathrm{mmol})$

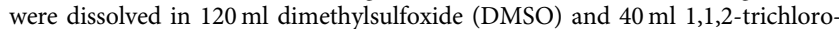
1,2,2-trifluoroethane in a $200 \mathrm{ml}$ Schlenk flask. The whole reaction was conducted under argon atmosphere. The solution was heated to $40^{\circ} \mathrm{C}$ and perfluorooctyl iodide $(3.4 \mathrm{ml}, 7.03 \mathrm{~g}, 12.9 \mathrm{mmol})$ was added. $60 \% \mathrm{H}_{2} \mathrm{O}_{2}(1.4 \mathrm{ml}, 1.67 \mathrm{~g}, 49 \mathrm{mmol})$ was added drop-wise over $5 \mathrm{~min}$. The solution turned red and formed black foam. After $30 \mathrm{~min}, 20 \mathrm{ml}$ 1,1,2-trichloro-1,2,2-trifluoroethane were added and the foam dissolved. One hour after the start of the reaction, a second portion perfluorooctyl iodide $(3.4 \mathrm{ml}, 7.03 \mathrm{~g}, 12.9 \mathrm{mmol})$ was added and $60 \% \mathrm{H}_{2} \mathrm{O}_{2}(1.4 \mathrm{ml}, 1.67 \mathrm{~g}$, $49 \mathrm{mmol}$ ) was added drop-wise over $5 \mathrm{~min}$. The reaction was continued for $1 \mathrm{~h}$, then the reaction mixture was cooled to room temperature, and the DMSO and 1,1,2-trichloro-1,2,2-trifluoroethane phases were separated. The 1,1,2-trichloro1,2,2-trifluoroethane phase was washed three times with $36 \%$ hydrochloric acid, once with water, and was dried over $\mathrm{Na}_{2} \mathrm{SO}_{4}$. After removing the solvent, $9.3 \mathrm{~g}$ reddish-brown oil were obtained. The product was purified on a silica-gel column with hexane and toluene as eluents. Yield: $700 \mathrm{mg}(13 \%) . R_{\mathrm{F}} 0.57$ with toluene. ${ }^{1} \mathrm{H} \mathrm{NMR}\left(300 \mathrm{MHz}, \mathrm{CDCl}_{3}+\right.$ Freon $\left.113(1: 1 \mathrm{v} / \mathrm{v}), \delta\right): 16.75(\mathrm{~s}, 1 \mathrm{H}), 8.77(\mathrm{~s}, 1 \mathrm{H})$, 8.15-8.00 (m, 2H), $7.86(\mathrm{~d}, J=7.9 \mathrm{~Hz}, 2 \mathrm{H}), 7.24(\mathrm{~d}, J=9.3 \mathrm{~Hz}, 2 \mathrm{H})$. DI-EI $(\mathrm{m} / \mathrm{z})$ : $1,031.98$ found, $1,031.98$ calculated.

Synthesis of HBANPF. HBANPF was prepared using the same procedure as HPhNPF, but with a fivefold excess of perfluorooctyl iodide, and the reaction mixture was stirred stirred for $2 \mathrm{~h}$ at $40^{\circ} \mathrm{C}$ and then overnight at room temperature. Yield $500 \mathrm{mg}(23 \%)$ starting from $0.5 \mathrm{~g}$ HBAN. $R_{\mathrm{F}} 0.69$ with hexane/toluene 2/1. ${ }^{1} \mathrm{H}$ NMR $\left(300 \mathrm{MHz}, \mathrm{CDCl}_{3}+\right.$ Freon $\left.113(1: 1 \mathrm{v} / \mathrm{v}), \delta\right): 17.01(\mathrm{~s}, 1 \mathrm{H}), 8.94$ $(\mathrm{s}, 1 \mathrm{H}), 8.79(\mathrm{~d}, J=8.2 \mathrm{~Hz}, 1 \mathrm{H}), 8.71(\mathrm{~d}, J=7.9 \mathrm{~Hz}, 1 \mathrm{H}), 8.52(\mathrm{~d}, J=8.3 \mathrm{~Hz}, 1 \mathrm{H})$, $8.03(\mathrm{~d}, J=8.2 \mathrm{~Hz}, 1 \mathrm{H}), 7.89(\mathrm{t}, J=7.6 \mathrm{~Hz}, 1 \mathrm{H}), 7.73(\mathrm{t}, J=7.5 \mathrm{~Hz}, 1 \mathrm{H})$. DI-EI $(\mathrm{m} / \mathrm{z})$ : $1,081.99$ found, $1,081.99$ calculated.

Synthesis of the aluminium complex of HPhNPF. HPhNPF (100 mg, $0.097 \mathrm{mmol}$ ) was dissolved in $20 \mathrm{ml} \mathrm{THF}$ and $20 \mathrm{ml}$ ethanol. $\mathrm{NaOH}(5.9 \mathrm{mg}$, $0.15 \mathrm{mmol})$ and $\mathrm{AlCl}_{3}(3.9 \mathrm{mg}, 29 \mu \mathrm{mol})$ were added and the reaction mixture was stirred for $2.5 \mathrm{~h}$ at $40^{\circ} \mathrm{C}$. Then the reaction was stopped the product was extracted with 1,1,2-trichloro-1,2,2-trifluoroethane and the organic phase was washed twice with water. The organic layer was dried over $\mathrm{Na}_{2} \mathrm{SO}_{4}$ and evaporated in vacuum. Five millilitres THF were added to the raw product and the mixture was placed in the freezer for a few hours. The THF phase was removed and new THF was added. The product was washed seven times following this procedure. Yield: $68.4 \mathrm{mg}$ (74\%). ${ }^{1} \mathrm{H}$ NMR $\left(300 \mathrm{MHz}, \mathrm{CDCl}_{3}+\right.$ Freon $\left.113(1: 1 \mathrm{v} / \mathrm{v}), \delta\right): 8.87-8.55(\mathrm{~m}, 3 \mathrm{H})$, 8.15-7.84 $(\mathrm{m}, 6 \mathrm{H}), 7.84-7.54(\mathrm{~m}, 3 \mathrm{H}), 7.42-7.04(\mathrm{~m}, 3 \mathrm{H})$; matrix assisted laser desorption ionisation (MALDI) $(\mathrm{m} / \mathrm{z}):[\mathrm{M}+\mathrm{Na}]^{+}: 3,142.93$ found, $3,142.90$ calculated. 
Synthesis of the aluminium complex of HBANPF. $A l(\mathrm{HBANPF})_{3}$ was prepared and purified with the same procedure as $\mathrm{Al}(\mathrm{HPhNPF})_{3}$. Yield $19.5 \mathrm{mg}(31 \%)$ starting from $80 \mathrm{mg} \mathrm{HBANPF} .{ }^{1} \mathrm{H}$ NMR $\left(300 \mathrm{MHz}, \mathrm{CDCl}_{3}, \delta\right): 9.2-8.2(\mathrm{~m}, 9.9 \mathrm{H})$, $8.06(\mathrm{~s}, 3 \mathrm{H}), 8.0-7.2(\mathrm{~m}, 7.2 \mathrm{H})$; MALDI $(\mathrm{m} / \mathrm{z}):[\mathrm{MH}]+: 3,271.11$ found, $3,270.96$ calculated, $\left(\mathrm{MH}\right.$ (with one additional $\mathrm{C}_{8} \mathrm{~F}_{17}$-group $\left.)\right)+: 3,689.02$ found, 3,688.92 calculated.

Preparation of the PS-based sensing materials. The sensor 'cocktails' contained the dyes $(0.02 \% \mathrm{w} / \mathrm{w}$ in respect to the polymer), PS $(5 \% \mathrm{w} / \mathrm{w}$ in respect to the solvent) and chloroform. These were knife-coated on a glass slide using a $175-\mu \mathrm{m}$ spacer. The resulting thickness for the dried layer is estimated to be $6 \mu \mathrm{m}$.

Preparation of the Hyflon AD 60-based sensing materials. Before coating, the glass slides were rendered hydrophobic with aquaphobe CF. The dyes $(0.05 \% \mathrm{w} / \mathrm{w}$ in respect to the polymer) and the polymer $(6 \% \mathrm{w} / \mathrm{w}$ in respect to the solvent) were dissolved in octafluorotoluene. Knife-coating on the glass slides using a $175-\mu \mathrm{m}$ spacer yielded a layer thickness of $\sim 12 \mu \mathrm{m}$. After a second coating with a $275-\mu \mathrm{m}$ spacer and evaporation of the solvent an $\sim 31-\mu \mathrm{m}$-thick layer was obtained.

Preparation of the Teflon AF 1600-based sensing materials. The sensors were prepared analogously to those based on Hyflon, but a 5\% w/w solution of the polymer in octafluorotoluene was used. The thickness of the sensing layer was estimated to be $24 \mu \mathrm{m}$.

Measurements. ${ }^{1} \mathrm{H}$ NMR spectra were recorded on a $300 \mathrm{MHz}$ instrument (Bruker). NOESY and HMBC spectra were acquired on an INOVA $500 \mathrm{MHz}$ NMR spectrometer (Varian). DMSO-d6 was used for HPhN and HBAN and the respective $\mathrm{BF}_{2}$ chelates and a mixture of 1,1,2-trichloro-1,2,2-trifluoroethane and $\mathrm{CDCl}_{3}(1: 1, \mathrm{v} / \mathrm{v})$ was used for perfluorinated ligands and the respective chelates. Electron impact (EI; $70 \mathrm{eV}$ ) and MALDI-TOF mass spectra were recorded on a Waters GCT Premier equipped with direct insertion (DI) and on a Micromass TofSpec 2E, respectively. Absorption spectra were acquired on a Cary 50 UV-VIS spectrophotometer from Varian and the emission spectra on a Fluorolog 3 fluorescence spectrometer from Horiba Scientific equipped with a R2658 photomultiplier from Hamamatsu. The absolute luminescence quantum yields were determined using an integrating sphere from Horiba. The luminescence decay times for the sensing materials were measured with the Fluorolog 3 spectrometer in kinetic acquisition mode. Calibrations were obtained using a temperaturecontrolled flow-through cell combined with a gas-mixing device from Voegtlin (Switzerland; www.red-y.com), which was used to mix nitrogen with $0.1 \% \mathrm{O}_{2}$ test gas (for the boron chelates) and nitrogen with 20 p.p.m.v. $\mathrm{O}_{2}$ test gas (for the aluminium complexes). Calibrations for the aluminium complexes were further corrected for impurities in the nitrogen gas using a standard addition method, by measuring decay times under nitrogen und in oxygen-free sodium sulphite solution. The measured intensities under nitrogen were multiplied with the lifetime ratio (nitrogen/oxygen-free) to obtain the actual value for $I_{0}$. All calibration points were corrected by the obtained intrinsic oxygen contamination. For additional information on photophysical properties of the dyes, see Supplementary Figs 12-16. For NMR and mass spectroscopy analysis of the compounds in this article, see Supplementary Figs 17-28.

\section{References}

1. Tanno, K. An automatic recording analyzer for the determination of dissolved oxygen in boiler feed water. Bull. Chem. Soc. Jpn 37, 804-810 (1964).

2. Nakano, T., Hoshi, K. \& Baba, S. Effect of background gas environment on oxygen incorporation in TiN films deposited using UHV reactive magnetron sputtering. Vacuum 83, 467-469 (2008).

3. Berger, H. Contamination due to process gases. Microelectron. Eng. 10, 259-267 (1991).

4. Longmuir, I. S. Respiration rate of bacteria as a function of oxygen concentration. Biochem. J. 57, 81-87 (1954).

5. Bergersen, F. J. \& Turner, G. L. Bacteriods from soybean root nodules: respiration and $\mathrm{N}_{2}$ fixation in flow-chamber reactions with oxyleghaemoglobin. Proc. R. Soc. Lond. Ser. B Bio. Sci. 238, 295-320 (1990).

6. Johnson, M. J. Aerobic microbial growth at low oxygen concentrations. J. Bacteriol. 94, 101-108 (1967).

7. Stolper, D. A., Revsbech, N. P. \& Canfield, D. E. Aerobic growth at nanomolar oxygen concentrations. Proc. Natl Acad. Sci. USA 107, 18755-18760 (2010).

8. Revsbech, N. P. et al. Determination of ultra-low oxygen concentrations in oxygen minimum zones by the STOX sensor. Limnol. Oceanogr. Methods 7 , 371-381 (2009).

9. Kochmann, S., Baleizão, C., Berberan-Santos, M. N. \& Wolfbeis, O. S. Sensing and imaging of oxygen with parts per billion limits of detection and based on the quenching of the delayed fluorescence of (13)C70 fullerene in polymer hosts. Anal. Chem. 85, 1300-1304 (2013).

10. Crank, J. \& Park, G. S. in Diffusion in Polymers 1-322 (Marcel Dekker Inc., 1996).

11. Quaranta, M., Borisov, S. M. \& Klimant, I. Indicators for optical oxygen sensors. Bioanal. Rev. 4, 115-157 (2012).
12. Wolfbeis, O. S. Materials for flourescence-based optical chemical sensors. J. Mater. Chem. 15, 2657-2669 (2005).

13. Amao, Y. Probes and polymers for optical sensing of oxygen. Microchim. Acta 143, 1-12 (2003).

14. Wang, X.-D. \& Wolfbeis, O. S. Optical methods for sensing and imaging oxygen: materials, spectroscopies and applications. Chem. Soc. Rev. 43, 3666-3761 (2014).

15. Nagl, S., Baleizão, C. \& Borisov, S. M. Optical sensing and imaging of trace oxygen with record response. Angew. Chem. 46, 2317-2319 (2007).

16. Zhang, G., Chen, J., Payne, S. J. \& Kooi, S. E. Multi-emissive difluoroboron dibenzoylmethane polylactide exhibiting intense fluorescence and oxygensensitive room-temperature phosphorescence. J. Am. Chem. Soc. 129, 8942-8943 (2007).

17. Zhang, G., Palmer, G. M., Dewhirst, M. W. \& Fraser, C. L. A dual-emissivematerials design concept enables tumour hypoxia imaging. Nat. Mater. 8, 747-751 (2009).

18. Xu, S. et al. Aromatic difluoroboron $\beta$-diketonate complexes: effects of $\pi$-conjugation and media on optical properties. Inorg. Chem. 52, 3597-3610 (2013).

19. Zhang, X. et al. General design strategy for aromatic ketone-based singlecomponent dual-emissive materials. ACS Appl. Mater. Interfaces 6, 2279-2284 (2014).

20. Borisov, S. M., Vasylevska, A. S., Krause, C. \& Wolfbeis, O. S. Composite luminescent material for dual sensing of oxygen and temperature. Adv. Funct. Mater. 16, 1536-1542 (2006).

21. Haddon, R. C., Rayford, R. \& Hirani, A. M. 2-Methyl-and 5-methyl-9hydroxyphenalenone. J. Org. Chem. 46, 4587-4588 (1981).

22. Haddon, R. C. Benzannelated 9-hydroxyphenalenones. Aust. J. Chem. 35, 1733 (1982).

23. Loudet, A. \& Burgess, K. BODIPY dyes and their derivatives: syntheses and spectroscopic properties. Chem. Rev. 107, 4891-4932 (2007).

24. Boens, N., Leen, V. \& Dehaen, W. Fluorescent indicators based on BODIPY. Chem. Soc. Rev. 41, 1130 (2012).

25. Polymer Handbook (eds Brandrup, J., Immergut, E. H. \& Grulke, E. A.) (Wiley, 1999).

26. Masuda, T., Isobe, E., Higashimura, T. \& Takada, K. Poly[1-(trimethylsilyl)-1propyne]: a new high polymer synthesized with transition-metal catalysts and characterized by extremely high gas permeability. J. Am. Chem. Soc. 105, 7473-7474 (1983).

27. Nagai, K. \& Nakagawa, T. Oxidation of poly(1-trimethylsilyl-1-propyne). J. Appl. Polym. Sci. 54, 1651-1658 (1994).

28. Nagai, K. \& Nakagawa, T. Effects of aging on the gas permeability and solubility in poly (1-trimethylsilyl-1-propyne) membranes synthesized with various catalysts. J. Membr. Sci. 105, 261-272 (1995).

29. Arcella, V., Ghielmi, A. \& Tommasi, G. High performance perfluoropolymer films and membranes. Ann. N. Y. Acad. Sci. 984, 226-244 (2003).

30. Nemser, S. M. \& Roman, I. C. Perfluorodioxole membranes, US Patent 5051114 A (1991).

31. Borisov, S. M., Lehner, P. \& Klimant, I. Novel optical trace oxygen sensors based on platinum(II) and palladium(II) complexes with 5,10,15,20-mesotetrakis-(2,3,4,5,6-pentafluorphenyl)-porphyrin covalently immobilized on silica-gel particles. Anal. Chim. Acta 690, 108-115 (2011).

\section{Acknowledgements}

The work was financially supported by the European Research Council (Project 'Oxygen', N 267233). We thank Professor R. Saf (Institute for Chemistry and Technology of Materials, Graz University of Technology) for acquiring mass spectra and Professor H. Weber (Institute of Organic Chemistry) for acquiring and analysis of the NOESY and HMBC NMR spectra.

\section{Author contributions}

P.L. designed the measurement setup, characterized the boron chelates and wrote the paper; C.S. synthesized the aluminium complexes, and did the related characterizations and calibrations; S.M.B. synthesized the boron chelates, discovered their interesting properties and performed the initial perfluoroalkylation studies; and I.K. supervised the project. All authors contributed substantially to discussion and planning.

\section{Additional information}

Supplementary Information accompanies this paper at http://www.nature.com/ naturecommunications

Competing financial interests: The authors declare no competing financial interests

Reprints and permission information is available online at http://npg.nature.com/ reprintsandpermissions/

How to cite this article: Lehner, P. et al. Ultra-sensitive optical oxygen sensors for characterization of nearly anoxic systems. Nat. Commun. 5:4460 doi: $10.1038 /$ ncomms5460 (2014) 